\title{
Ni-Catalyzed Stannylation of Aryl Esters via C-O Bond Cleavage
}

\section{Yiting Gu, and Ruben Martin*}

\begin{abstract}
A Ni-catalyzed stannylation of aryl esters with air- and moisture-insensitive silylstannyl reagents via $\mathrm{C}\left(\mathrm{sp}^{2}\right)-\mathrm{O}$ cleavage is described. This protocol is characterized by its wide scope, including challenging combinations, thus enabling access to versatile building blocks and orthogonal C-heteroatom bond-formations.
\end{abstract}

Owing to the low-cost, benign character and availability of phenol, C-O electrophiles have emerged as powerful alternatives to aryl halides in the cross-coupling arena. ${ }^{[1]}$ Although predisposed to site-selectivity issues with multiple $\mathrm{C}-\mathrm{O}$ reaction sites, aryl esters have become attractive counterparts due to their accessibility, thermal/moisture stability and exquisite orthogonality with aryl halides, representing an added value when compared to highly reactive organic sulfonates. ${ }^{[1]}$ In contrast to commonly practiced $\mathrm{C}-\mathrm{C}$ bond-formations using organometallic species (Scheme 1 , path a), ${ }^{[2,3]}$ the paucity of $\mathrm{C}_{-}$ heteroatom bond-formations of aryl esters is certainly striking (Scheme 1, path b), ${ }^{[4]}$ a testament to the attenuated reactivity of heteroatom-based nucleophiles. Undoubtedly, such void terrain constitutes a unique opportunity for discovering new fundamental reactivity while expanding our synthetic repertoire for accessing essential molecular architectures.

$\square$ Catalytic C-O cleavage reactions of aryl esters

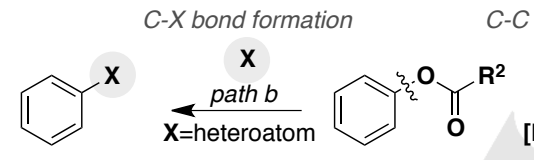

no $\mathrm{R}-[\mathrm{M}]$ required

- limited precedents

$\square$ This work: catalytic stannylation of aryl esters via C-O cleavage

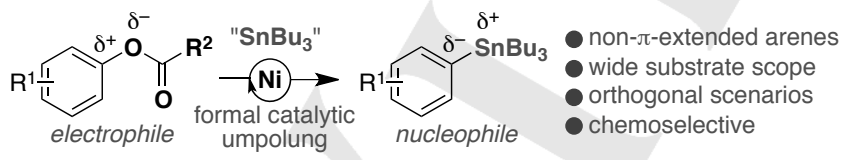

Scheme 1. Catalytic C-O Bond-Cleavage of Aryl Esters.

At present, the existing precedents for $\mathrm{C}$-heteroatom bondformation of aryl esters via $\mathrm{C}-\mathrm{O}$ cleavage remain essentially confined to $\mathrm{C}-\mathrm{P}$ and $\mathrm{C}-\mathrm{N}$ bond-formations. ${ }^{[4 \mathrm{a}, 4 \mathrm{~d}]}$ Aimed at providing better flexibility in synthetic design via further derivatization techniques, aryl esters have recently been converted to aryl trialkylsilanes or aryl boronates via $\mathrm{C}-\mathrm{O}$ cleavage ${ }^{[4 \mathrm{~b}, 4 \mathrm{cc}]}$ unfortunately, a limited number of transformations are amenable via $\mathrm{C}-\mathrm{Si}$ bond-cleavage of aryl trialkyl silanes, whereas high temperatures and noble catalysts are needed to forge $\mathrm{C}-\mathrm{B}$ bonds from aryl esters, thus reinforcing a change in strategy. Prompted by our interest in $\mathrm{C}-\mathrm{O}$ functionalization, ${ }^{[4,5]}$ we questioned whether an umpolung strategy could be designed to convert electrophilic aryl esters into nucleophilic organotin reagents, superb reaction intermediates via C-Sn cleavage (Scheme 1, bottom). ${ }^{[6]}$ Indeed, the Migita-Kosugi-Stille (MKS) reaction of organotin reagents remains one of the most robust, versatile, mild and widely applicable cross-couplings. ${ }^{[7]}$ Not surprisingly, the MKS reaction is frequently used in total synthesis of natural products ${ }^{[8]}$ or in densely functionalized polyheterocyclic cores, ${ }^{[9]}$ privileged motifs in a wide variety of pharmaceuticals that are not particularly trivial to assemble via classical cross-coupling reactions. ${ }^{[10]}$ Herein, we describe a new $\mathrm{Ni}$-catalyzed stannylation of aryl esters via $\mathrm{C}\left(\mathrm{sp}^{2}\right)-\mathrm{O}$ cleavage. The transformation is distinguished by its wide scope, including the coupling of non- $\pi$-extended arenes or even heterocyclic cores, setting the basis for designing iterative cross-coupling scenarios as well as further derivatization techniques via $\mathrm{C}-\mathrm{Sn}$ cleavage. Initial mechanistic studies suggest that a catalytic cycle initiated by oxidative addition comes into play.

[a] Y. Gu, Prof. R. Martin

Institute of Chemical Research of Catalonia (ICIQ)

The Barcelona Institute of Science and Technology

Av. Països Catalans 16, 43007 Tarragona (Spain)

E-mail: rmartinromo@iciq.es

[b] Prof. R. Martin

ICREA, Passeig Lluïs Companys, 23, 08010 Barcelona Spain 


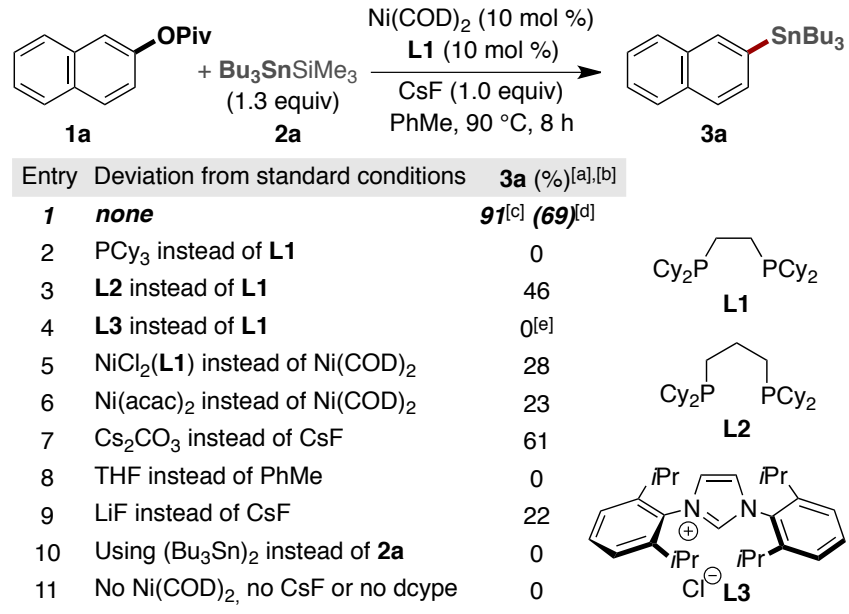

Scheme 2. Optimization of the Reaction Conditions. [a] 1a $(0.20 \mathrm{mmol}), 2 \mathrm{a}$ (0.26 mmol), Ni(COD) 2 (10 mol\%), L1 (10 mol\%), CsF (0.20 mmol) in PhMe $(0.20 \mathrm{M})$ at $90^{\circ} \mathrm{C}$. [b] GC yields using decane as internal standard. [c] Isolated yield. [d] $\mathrm{Ni}(\mathrm{COD})_{2}(5 \mathrm{~mol} \%)$. [e] with $\mathrm{NaOtBu}(20 \mathrm{~mol} \%)$.

We started our investigations by reacting $\mathbf{1 a}$ with $\mathbf{2} \mathbf{a}$, a benchstable stannyl reagent that can be prepared quantitatively in one-step and in bulk quantities (Scheme 2). ${ }^{[11-13]}$ After systematic experimentation, ${ }^{[14]}$ a combination of $\mathrm{Ni}(\mathrm{COD})_{2}, \mathbf{L 1}$ and $\mathrm{CsF}$ in toluene at $90^{\circ} \mathrm{C}$ provided the best results, affording $3 \mathbf{a}$ in $91 \%$ isolated yield (entry 1 ). In line with our expectations, the nature of the ligand proved to be critical. While traces of $\mathbf{3 a}$, if any, were observed with $\mathrm{PC}_{3}$ and L3 that have shown to be particularly useful in a myriad of $\mathrm{C}-\mathrm{O}$ bond-functionalization techniques (entries 2 and 4$),{ }^{[1]}$ the use of structurally related L2 resulted in considerably lower yields of $\mathbf{3 a}$ (entry 3 ). Although $\mathbf{2 a}$ could serve as a sacrificial reducing agent, lower results were found when using $\mathrm{Ni}(\mathrm{II})$ precatalysts, suggesting that $\mathrm{COD}$ might be stabilizing the transient metal species within the catalytic cycle. ${ }^{[15]}$ Similarly, a significant erosion in yield was observed when using solvents, bases and stannyl reagents other than toluene, CsF or 2a (entries 7-10). As expected, rigorous control experiments demonstrated that all of the reaction parameters were crucial for the stannylation to occur (entry 11). ${ }^{[16]}$

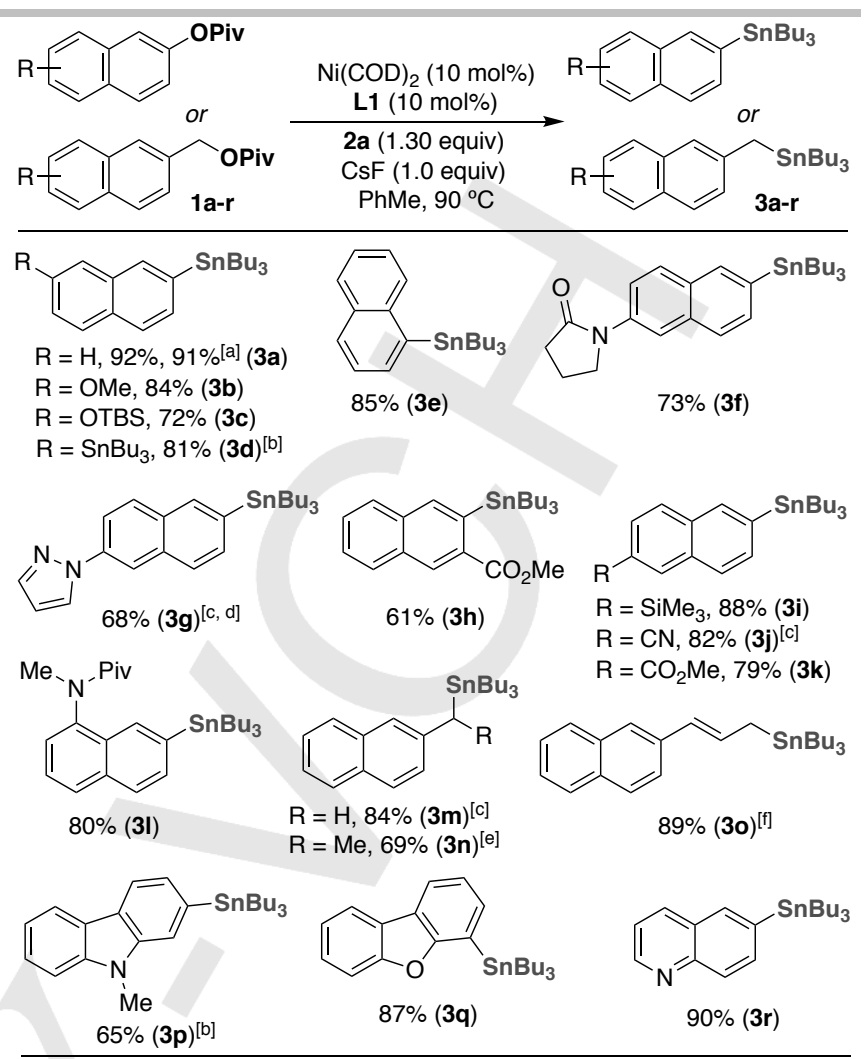

Scheme 3. Scope of $\pi$-extended aromatic pivalates. Reaction conditions: as scheme 2, entry 1; Yields of Isolated products, average of at least two independent runs. ${ }^{\text {[a] }} 1 \mathrm{a}(5.0 \mathrm{mmol}) .{ }^{[b]} \mathbf{2 a}\left(2.3\right.$ equiv). ${ }^{[\mathrm{cl}} \mathrm{t}=6 \mathrm{~h} .{ }^{[\mathrm{d}]} \mathbf{2 a}(2.0$ equiv). ${ }^{[\mathrm{e}]} \mathrm{T}=110^{\circ} \mathrm{C} .{ }^{[\mathrm{ff}]} 1$-(naphthalen-2-yl)allyl pivalate (10) as substrate.

As shown in Scheme 3, our stannylation event turned out to be widely applicable regardless of the electronic and steric environments on the aryl ring. ${ }^{[17]}$ Interestingly, amides (3f), silyl ethers $(\mathbf{3} \mathbf{c})$, aryl silanes $(\mathbf{3 i})$, nitriles $(\mathbf{3} \mathbf{j})$, esters (3h and $\mathbf{3 k}$ ), carbazoles $(\mathbf{3 p})$, carbamates $(3 \mathbf{l})$ or benzofurans $(\mathbf{3 q})$ could all perfectly be accommodated. Notably, the stannylation of $\mathbf{1 a}$ could be executed at gram scale $(5 \mathrm{mmol})$ without noticeable erosion in yield. As shown for $\mathbf{3 d}$, a two-fold stannylation event could be easily within reach by carefully adjusting the stoichiometry of the reaction. Although heterocycles containing nitrogen donors could potentially hinder the reaction, this was not the case $(\mathbf{3 g}, \mathbf{3 r})$. Notably, the reaction could be extended to primary or secondary benzylic pivalates possessing $\beta$-hydrogens delivering $3 \mathrm{~m}$ and $3 \mathrm{n}$ in good yields. In addition, the use of 1 (naphthalen-2-yl)allyl pivalate gave rise to 30 in $89 \%$ yield. To put these results into perspective, $3 \mathrm{~m}-\mathbf{3 0}$ could not be obtained in the absence of Ni catalyst. 


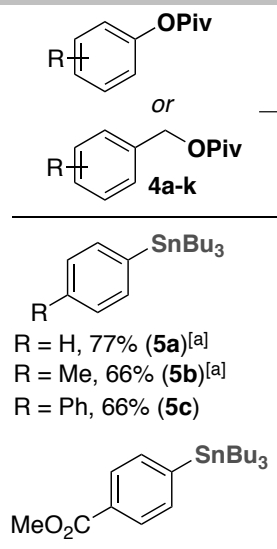

$62 \%(5 h)$

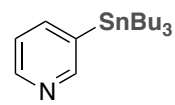

$59 \%(\mathbf{5 k})$ L1 (10 mol\%)

2a (1.30 equiv)

CsF (1.0 equiv) $\mathrm{PhMe}, 90^{\circ} \mathrm{C}$<smiles>[R]c1cccc(S(C)(C)CC)c1</smiles>

$\mathrm{R}=\mathrm{F}, 61 \%(\mathbf{5 d})$

$\mathrm{R}=\mathrm{CO}_{2} \mathrm{Me}, 71 \%(\mathbf{5 e})$

$\mathrm{R}=\mathrm{CF}_{3}, 80 \%(5 \mathrm{f})$

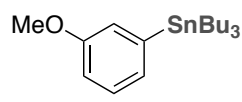

$73 \%(5 i)$

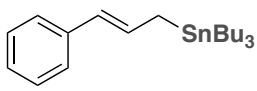

$82 \%(5 \mathrm{I})$

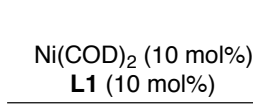

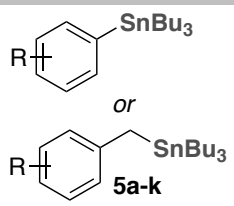

$\overbrace{\mathrm{Ph}}^{\mathrm{SnBu}_{3}}$

$57 \%(5 \mathrm{~g})$

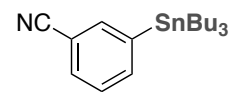

$62 \%(5 \mathbf{j})^{[a]}$

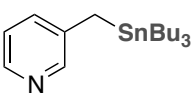

$65 \%(5 \mathrm{~m})^{[a]}$
Scheme 4. Scope of non $\pi$-extended aryl pivalates. Reaction conditions: as scheme 2, entry 1; Yields of Isolated products, average of at least two independent runs. ${ }^{\text {[a] }} \mathbf{2 a}$ (2.0equiv).

Despite the formidable advances realized in $\mathrm{C}-\mathrm{O}$ functionalization, the utilization of non- $\pi$-extended coupling counterparts is not as commonly practiced as one might anticipate. ${ }^{[18]}$ As shown in Scheme 4, we found that our stannylation protocol could equally be applied for regular aryl pivalates. In line with our expectations, the stannylation could be performed independently of whether electron-rich or electronpoor substituents were located at either meta, para or ortho position. Likewise, aryl pivalates containing esters $(\mathbf{5 e}, 5 \mathbf{h})$, nitriles $(\mathbf{5 j})$ or aryl fluorides $(\mathbf{5 d})$ could be coupled with similar ease. Notably, extensions to benzyl or allyl pivalates posed no problems (5I and $\mathbf{5 m}) \cdot{ }^{[19]}$ Particularly interesting was the ability to tolerate the presence of heterocycle cores containing basic nitrogen donors, as these motifs could compete with L1 for metal binding (5k and $\mathbf{5 m}$ ).

Next, we questioned whether we could implement orthogonal scenarios in the presence of aryl halides with conventional $\mathrm{Cu}$ or $\mathrm{Pd}$ catalysts (Scheme 5, top). Specifically, we found that a Cucatalyzed amidation took place exclusively at the aryl bromide terminus (7). ${ }^{[20]}$ A subsequent Pd-catalyzed Suzuki-Miyaura protocol based on XPhos resulted in $\mathbf{8},{ }^{[21]}$ that was ultimately exposed under our stannylation protocol to cleanly afford $\mathbf{9}$. These results represent a testament to the robustness of aryl esters, an added value when compared to their organic sulfonate congeners. The synthetic applicability of our stannylation protocol is further illustrated in Scheme 5 (bottom). As shown, $\mathbf{1 0}$ or $\mathbf{1 1}$ could be easily prepared from $\mathbf{3 a}$ upon treatment with either NFSI or iodine, thus representing a formal ipso-halogenation of aryl esters. Although polyheterocyclic motifs are traditionally difficult to assemble via classical $\mathrm{Pd}$ catalyzed cross-coupling reactions, ${ }^{[10]}$ we found that 12 or 13 could be obtained in high yields under neutral conditions with $\mathrm{Pd}\left(\mathrm{PPh}_{3}\right)_{4}$ as catalyst, thus demonstrating the generality and flexibility of the Migita-Kosugi-Stille coupling when compared to other cross-coupling reactions for assembling rather sophisticated backbones. Taken together, the results of Schemes 3-5 show the prospective impact of this methodology.

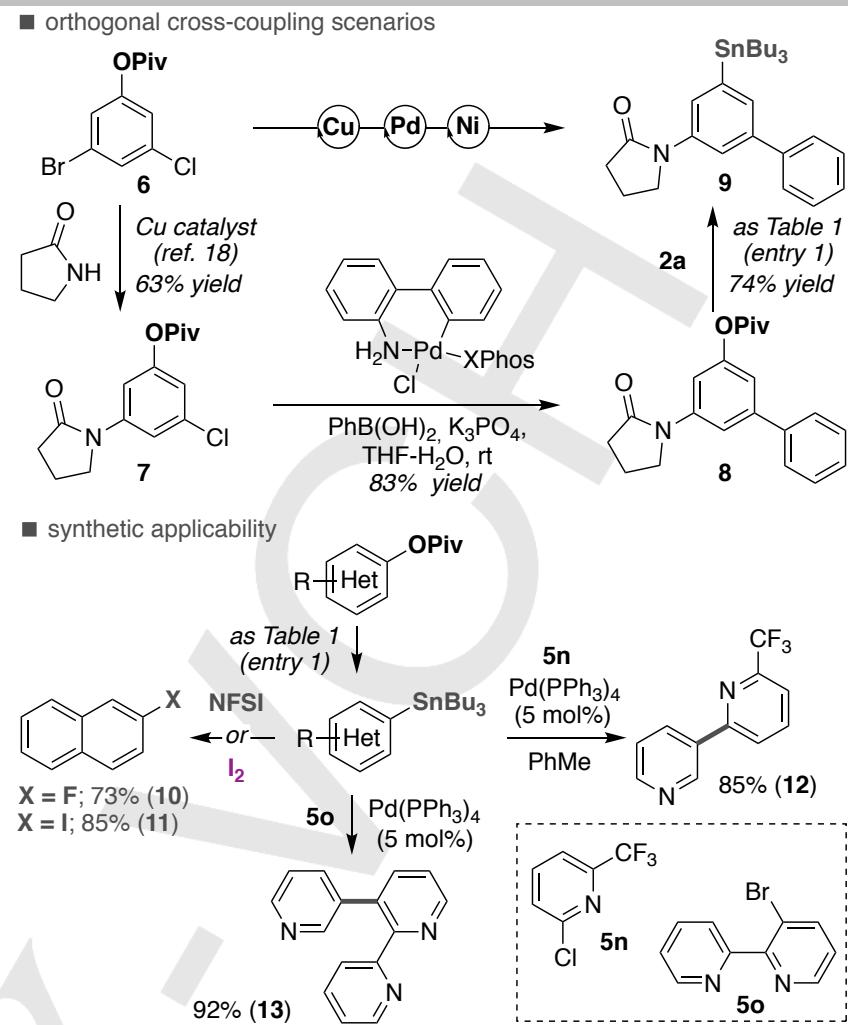

Scheme 5. Orthogonal Scenarios and Synthetic Applicability.

stoichiometric \& catalytic studies with $\mathbf{N i - 1}$

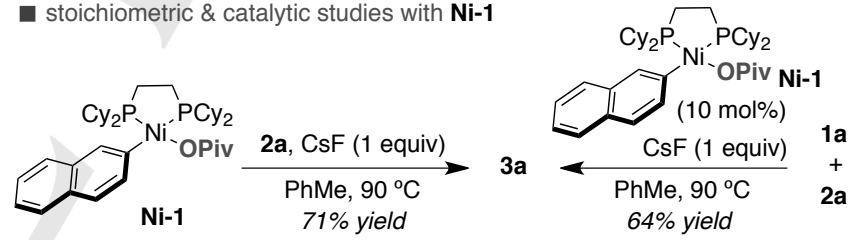

mechanistic proposal

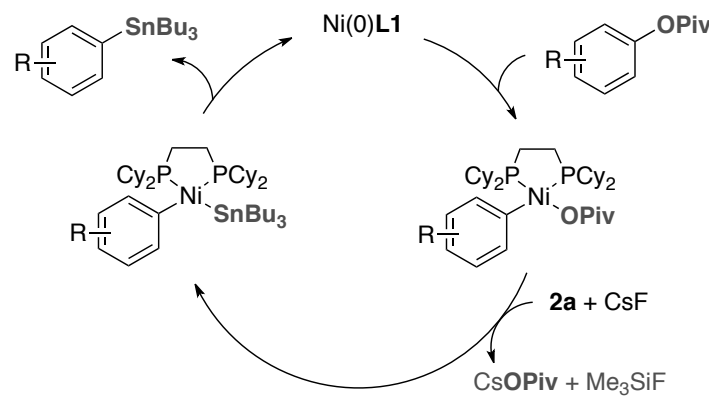

Scheme 6. Mechanistic Considerations.

Although unraveling all mechanistic intricacies of this transformation should await further investigations, we decided to study the reactivity of the putative oxidation species, as $\mathbf{N i - 1}$ could be readily prepared upon exposure of $1 \mathrm{a}$ to $\mathrm{Ni}(\mathrm{COD})_{2}$ and L1. ${ }^{[22],[23]}$ Interestingly, Ni-1 was found to be competent as reaction intermediate, as $3 a$ was invariably formed in good yields regardless of whether $\mathbf{~ N i - 1 ~ w a s ~ u s e d ~ i n ~ a ~ s t o i c h i o m e t r i c ~ o r ~}$ in a catalytic manner (Scheme 6). Although we cannot rigorously rule out other conceivable scenarios, ${ }^{[24]}$ at present we propose a mechanistic rationale based on the initial formation of $\mathrm{Ni}-1$ 
followed by transmetallation of 2 a mediated by fluoride source. ${ }^{[25}$ A final $\mathrm{C}-\mathrm{Sn}$ bond reductive elimination event would deliver the aryltin derivative while recovering back the active propagating $\mathrm{Ni}(0)$ L1 species. $^{[26],[27]}$

In summary, we have documented an unconventional $\mathrm{Ni}$ catalyzed stannylation of aryl esters, representing a step-forward towards implementing heteroatom-based nucleophiles in $\mathrm{C}-\mathrm{O}$ bond-cleavage, thus contributing to expand the rather limited portfolio of $\mathrm{C}$-heteroatom bond-forming reactions via $\mathrm{C}-\mathrm{O}$ functionalization. The salient features of this protocol are the broad scope and excellent chemoselectivity profile, allowing for the use of non- $\pi$-extended arenes or heteroaryl motifs, even in iterative-type scenarios. Further extensions to other $\mathrm{C}-\mathrm{O}$ electrophiles are currently underway in our laboratories.

\section{Acknowledgements}

We thank ICIQ, the European Research Council (ERC-277883), MINECO (CTQ2015-65496-R \& Severo Ochoa Excellence Accreditation 2014-2018, SEV-2013-0319) and Cellex Foundation for support. Johnson Matthey, Umicore and Nippon Chemical Industrial are acknowledged for a gift of metal \& ligand sources. Y. G. thanks Severo Occhoa for a scholarship.

\section{Keywords: cross-coupling $\bullet$ nickel $\cdot$ aryl ester $\cdot \mathrm{C}-\mathrm{O}$ cleavage}

[1] a) C. Zarate, M. Van Gemmeren, R. J. Somerville, R. Martin, Adv. Organomet. Chem. 2016, 66, 143-222. b) M. Tobisu, N. Chatani, Acc. Chem. Res. 2015, 48, 1717-1726. c) E. J. Tollefson, L. E. Hanna, E. R. Jarvo, Acc. Chem. Res. 2015, 48, 2344-2353. d) B. Su, Z.-C. Cao, Z.J. Shi, Acc. Chem. Res. 2015, 48, 886-896. e) J. Cornella, C. Zarate, R. Martin, Chem. Soc. Rev. 2014, 43, 8081-8097. f) J. Yamaguchi, K Muto, K. Itami, Eur. J. Org. Chem. 2013, 19-30. g) B. M. Rosen, K. W. Quasdorf, D. A. Wilson, N. Zhang, A.-M. Resmerita, N. K. Garg, V. Percec, Chem. Rev. 2011, 111, 1346-1416.

[2] Selected $\mathrm{C}-\mathrm{C}$ bond-formations using aryl esters and well-defined organometallic reagents: a) L. Guo, C.-C. Hsiao, H. Yue, X. Liu, M Rueping, ACS Catal. 2016, 6, 4438-4442. b) G. A. Molander, F. Beaumard, Org. Lett. 2010, 12, 4022-4025. c) K. W. Quasdorf, X. Tian, N. K. Garg, J. Am. Chem. Soc. 2008, 130, 14422-14423. d) B.-J. Li, Y.Z. Li, X,-Y. Lu, J. Liu, B.-T. Guan, Z.-J. Shi, Angew. Chem. Int. Ed. 2008, 47, 10124-10127; Angew. Chem. 2008, 120, 10278-10281. e) B.T. Guan, Y. Wang, B.-J. Li, D.-G, Yu, Z.-J. Shi, J. Am. Chem. Soc. 2008, 130, 14468-14470.

[3] Selected references using other carbon-based nucleophiles: a) J. Cornella, E. P. Jackson, R. Martin, Angew. Chem. Int. Ed. 2015, 54, 4075-4078; Angew. Chem. 2015, 127, 4147-4150. b) R. Taksie, K. Muto, J. Yamaguchi, K. Itami, Angew. Chem. Int. Ed. 2014, 53, 6791 6794; Angew. Chem. 2014, 126, 6909-6912. c) K. Muto, J. Yamaguchi, K. Itami, J. Am. Chem. Soc. 2012, 134, 169-172. d) A. R. Ehle, Q. Zhou, M. P. Watson, Org. Lett. 2012, 14, 1202-1205.

[4] a) J. Yang, T. Chen, L.-B. Han, J. Am. Chem. Soc. 2015, 137, 17821785. b) H. Kinuta, J. Hasegawa, M. Tobisu, N. Chatani, Chem. Lett. 2015, 44, 366-368. c) C. Zarate, R. Martin, J. Am. Chem. Soc. 2014, 136, 2236-2239. d) T. Shimasaki, M. Tobisu, N. Chatani, Angew. Chem. Int. Ed. 2010, 49, 2929-2932; Angew. Chem. 2010, 122, 2991-2994.

[5] Selected references: a) C. Zarate, M. Nakajima, R. Martin, J. Am. Chem. Soc. 2017, DOI: 10.1021/jacs.6b10998. b) C. Zarate, R. Manzano, R. Martin, J. Am. Chem. Soc. 2015, 137, 6754-6757. c) A. Correa, T. León, R. Martin, J. Am. Chem. Soc. 2014, 136, 1062-1069. d) A. Correa, R. Martin, J. Am. Chem. Soc. 2014, 136, 7253-7256. e) J. Cornella, E. Gómez-Bengoa, R. Martin, J. Am. Chem. Soc. 2013, 135,
1997-2009. f) P. Alvarez-Bercedo, R. Martin, J. Am. Chem. Soc. 2010, 132, 17352-17353.

[6] See for example: a) A. G. Davies, M. Gielen, K. H. Pannell, E. R. Tiekink, Tin Chemistry: Fundamentals Frontiers and Applications, $1^{\text {st }}$ ed.; Wiley: Chichester, U.K., 2008. b) H. Yoshida, Synthesis 2016, 48, 2540-2552. c) K. J. Makaravage, A. F. Brooks, A. V. Mossine, M. S. Sanford, P. J. H. Scott, Org. Lett. 2016, 18, 5440-5443. d) C. Huang, T. Liang, S. Harada, E. Lee, T. Ritter, J. Am. Chem. Soc. 2011, 133, 13308-13310. e) P. Tang, T. Furuya, T. Ritter, J. Am. Chem. Soc. 2010, 132, 12150-12154. f) T. Furuya, A. E. Strom, T. Ritter, J. Am. Chem. Soc. 2009, 131, 1662-1663. g) A. Donovan, J. Forbes, P. Dorff, P. Schaffer, J. Babich, J. F. Valliant, J. Am. Chem. Soc. 2006, 128, 35363537, and citations therein.

[7] For selected review, see: a) C. Cordovilla, C. Bartolomé, J. M. Martínez-llarduya, P. Espinet, ACS Catal. 2015, 5, 3040-3053. b) P Espinet, A. M. Echavarren, Angew. Chem. Int. Ed. 2004, 43, 4704-4734; Angew. Chem. 2004, 116, 4804-4839. c) J. Hassan, M. Sevignon, C. Gozzi, E. Schulz, M. Lemaire, Chem. Rev. 2002, 102, 1359-1470.

[8] For selected examples: a) M. M. Logan, T. Toma, R. Thomas-Tran, J. Du Bois, Science 2016, 354, 865-869. b) J. Li, P. Yang, M. Yao, J. Deng, A. Li, J. Am. Chem. Soc. 2014, 136, 16477-16480. c) D. Mailhol, J. Willwacher, N. Kausch-Busies, E. E. Rubitski, Z. Sobol, M. Schuler, M.-H. Lam, S. Musto, F. Loganzo, A. Maderna, A. Fürstner, J. Am. Chem. Soc. 2014, 136, 15719-15729. d) G. Valot, C. S. Regens, D. P. O'Malley, E. Godineau, H. Takikawa, A. Fürstner, Angew. Chem. Int. Ed. 2013, 52, 9534-9538; Angew. Chem. 2013, 125, 9713-9717. e) E. Alonso, H. Fuwa, C. Vale, Y. Suga, T. Goto, Y. Konno, M. Sasaki, F. M. LaFerla, M. R. Vieytes, L. Giménez-Llort, L. M. Botana, J. Am. Chem. Soc. 2012, 134, 7467-7479.

[9] a) J. Kim, H. Kim, S. B. Park, J. Am. Chem. Soc. 2014, 136, 1462914638. b) T. Eicher, S. Hauptmann, The Chemistry of Heterocycles Structure, Reactions, Synthesis and Application, VCH, Weinheim, 2003.

[10] For an illustrative large-scale application (>50 g scale) of Pfizer in which a densely functionalized polyheterocyclic core could only be accessed by Migita-Kosugi-Stille reaction: J. A. Ragan, J. W. Raggon, P. D. Hill, B. P. Jones, R. E. McDermott, M. J. Muchhof, M. A. Marx, J. M. Casavant, B. A. Cooper, J. L. Doty, Y. Lu, Org. Process Res. Dev. 2003, 7, 676-683. For an additional example by Merck producing $1.5 \mathrm{Kg}$ via Migita-Kosugi-Stille coupling: N. Yasuda, C. Yang, K. M. Wells, M. S. Jensen, D. L. Hughes, Tetrahedron Lett. 1999, 40, 427-430.

[11] For the synthesis of 2a, see: D.-Y. Wang, C. Wang, M. Uchiyama, J. Am. Chem. Soc. 2015, 137, 10488-10491.

[12] For selected references using 2a in organic synthesis: a) R. R. Singidi, A. M. Kutney, J. C. Gallucci, T. V. RajanBabu, J. Am. Chem. Soc. 2010, 132, 13078-13087. b) S. Gréau, B. Radetich, T. V. RajanBabu, J. Am. Chem. Soc. 2000, 122, 8579-8580. c) M. Mori, N. Kaneta, M. Shibasaki, J. Org. Chem. 1991, 56, 3486-3493.

[13] For elegant silylstannylation techniques of alkenes, but not employing 2a as reagent, see: H. Yoshida, Y. Hayashi, Y. Ito, K, Takaki, Chem. Commun. 2015, 51, 9440-9442.

[14] For details, see Supporting Information

[15] See for example: a) A. Fürstner, K. Majima, R. Martin, H. Krause, E. Kattnig, R. Goddard, W. Lehmann, J. Am. Chem. Soc. 2008, 130, 1992-2004. b) ref. 4e.

[16] Notably, no homocoupling was observed by Migita-Kosugi-Stille coupling of in situ generated 3a with 1a. For a recent Migita-KosugiStille coupling of unconventional cross-coupling partners: D.-Y. Wang, M. Kawahata, Z.-K. Yang, K. Miyamoto, S. Komagawa, K. Yamaguchi, C. Wang, M. Uchiyama, Nat. Commun. 2016, 7, No. 12937.

[17] The mass balance of the reactions accounts for unreactive starting material and reduced product

[18] Selected catalytic C-O bond-cleavage limited to the use of $\pi$-extended systems: a) H. M. Wisniewska, E. C. Swift, E. R. Jarvo, J. Am. Chem. Soc. 2013, 135, 9083-9090. b) Q. Zhou, H. D. Srinivas, S. Dasgupta, M. P. Watson, J. Am. Chem. Soc. 2013, 135, 3307-3310. c) B. L. Taylor, M. R. Harris, E. R. Jarvo, Angew. Chem., Int. Ed. 2012, 51, 7790-7793; Angew. Chem. 2012, 124, 1-5. d) B. L. H. Taylor, E. C. Swift, J. D. Waetzig, E. R. Jarvo, J. Am. Chem. Soc. 2011, 133, 389-391. e) D.-G. Yu, Z.-J. Shi, Angew. Chem., Int. Ed. 2011, 50, 7097-7100; Angew. Chem. 2011, 123, 7235-7238. f) D.-G. Yu, B.-J. Li, S.-F. Zheng, B.-T 
Guan, B.-Q. Wang, Z.-J. Shi, Angew. Chem., Int. Ed. 2010, 49, 45664570; Angew. Chem. 2010, 122, 4670-4674.

[19] No reaction occurred in the absence of $\mathrm{Ni}(\mathrm{COD})_{2} / \mathrm{L} 1$.

[20] A. Klapars, X. Huang, S. L. Buchwald, J. Am. Chem. Soc. 2002, 124, 7421-7428.

[21] T. Kinzel, Y. Zhang, S. L. Buchwald, J. Am. Chem. Soc. 2010, 132, 14073-14075.

[22] K. Muto, J. Yamaguchi, A. Lei, K. Itami, J. Am. Chem. Soc. 2013, 135 , 16384-16387

[23] A slightly modified procedure to that used in ref. 21 was followed to prepare $\mathbf{~ N i - 1 ~ i n ~ l a r g e ~ a m o u n t s . ~ S e e ~ r e f . ~} 14$.

[24] The available experimental data does not allow us to rule out the intermediacy of $\mathrm{Ni}(\mathrm{I})$ intermediates generated by comproportionation events. See for example, ref. $5 \mathrm{~d}$.

[25] This notion gains credence by in situ monitoring the reaction of $1 \mathrm{a}$ with $2 \mathbf{a}$ and $\mathrm{Ni}(\mathrm{COD})_{2} / \mathbf{L} \mathbf{1}$, observing the clean formation of $\mathbf{N i}-\mathbf{1}$ in the crude reaction mixture. See ref. 14

[26] $\mathrm{Me}_{3} \mathrm{SiF}$ was formed quantitatively, as judged by ${ }^{19} \mathrm{~F}-\mathrm{NMR}$ and ${ }^{29} \mathrm{Si}$ NMR spectroscopy. Likewise, ${ }^{113} \mathrm{Cs}-\mathrm{NMR}$ and ${ }^{1} \mathrm{H}-\mathrm{NMR}$ corroborated the formation of CsOPiv as byproduct.

[27] Stoichiometric experiments with $2 \mathrm{a}$ and $\mathrm{Ni}(\mathrm{COD})_{2} / \mathrm{L} 1$ revealed that $\mathrm{Ni}(\mathrm{COD}) \mathrm{L} 1$ was formed quantitatively, thus ruling out an alternative scenario consisting of an oxidative addition of $\mathrm{Ni}(0)$ into the $\mathrm{Sn}-\mathrm{Si}$ bond For an oxidative addition of silylstannanes to other $d^{10}$ metals, see: $T$. Sagawa, Y. Sakamoto, R. Tanaka, H. Katayama, F. Ozawa Organometallics 2003, 22, 4433-4445. 


\section{COMMUNICATION}

Ni-catalyzed stannylation of aryl esters via $\mathrm{C}\left(s p^{2}\right)-O$ cleavage<smiles>COc1ccccc1</smiles>

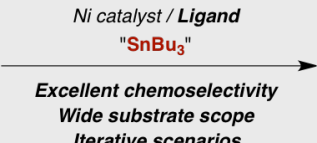

Wide substrate scope

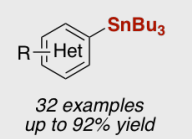

$\mathrm{Cy}_{2} \mathrm{P}$ Ligand
A versatile and widely applicable $\mathrm{Ni}$-catalyzed stannylation of aryl esters has been developed, contributing to expand the rather limited portfolio of C-heteroatom bond-formations via $\mathrm{C}-\mathrm{O}$ functionalization. The reaction is characterized by its excellent chemoselectivity profile and broad substrate scope, including challenging substrate combinations and iterative techniques that shows the prospective impact of this methodology in complex settings.
Yiting Gu, Ruben Martin*

Page No. - Page No.

Title

$\mathrm{Ni}$-Catalyzed stannylation of aryl

esters via $\mathrm{C}-\mathrm{O}$ bond cleavage 